[News]

\title{
《物理化学学报》创刊三十周年纪念大会 暨第四届编委会会议与物理化学前沿学术研讨会召开
}

2015 年 7 月 3 日至 4 日, 《物理化学学报》(英文名称Acta Physico-Chimica Sinica, 以下简称学报)创 刊三十周年纪念大会暨第四届编委会会议与物理化学前沿学术研讨会在北京大学化学与分子工程学 院召开。受邀嘉宾、新一届编委会成员和北京大学化学与分子工程学院师生员工约 200 余人出席纪念 大会。会议由《物理化学学报》新一届主编刘忠范院士主持。

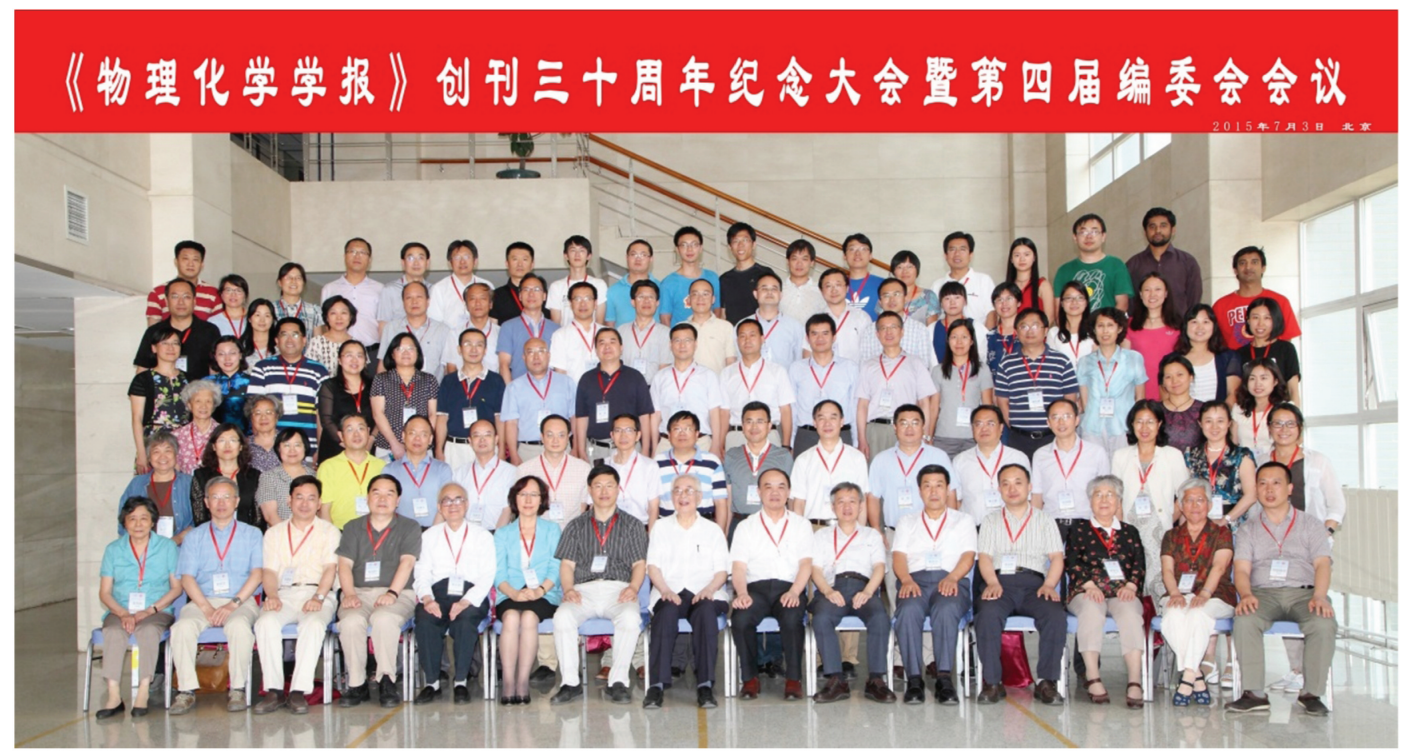

与会代表合影

在 7 月 3 日下午 2 点召开的《物理化学学报》创刊三十周年纪念大会上, 学报主管单位代表、中国科 学技术协会书记处书记吴海鹰教授, 学报主办单位代表、中国化学会理事长姚建年院士, 学报编委代 表、2013 年国家最高科学技术奖获得者张存浩院士, 国家自然科学基金委员会化学科学部三处(物理化 学) 处长杨俊林研究员, 《化学通报》主编、中国科学院化学研究所所长张德清研究员, 北京大学化学与 分子工程学院院长高毅勤教授, 以及北京大学副校长高松院士等嘉宾先后致辞。他们充分肯定《物理 化学学报》在过去三十年中取得的突出成绩, 称赞学报为我国物理化学及相关学科科技工作者们的竭 诚服务, 为提升我国物理化学研究质量和加强学科学术交流提供了良好的平台。代表们希望《物理化 学学报》在已有成绩基础上, 发扬 “以服务求支持, 以贡献求发展” 的办刊理念, 不断创新、与时俱进、坚 持特色, 进一步提高办刊质量, 更好地服务于我国广大物理化学及相关学科的研究人员和读者, 将《物 理化学学报》早日办成具有国际先进水平的科技期刊。

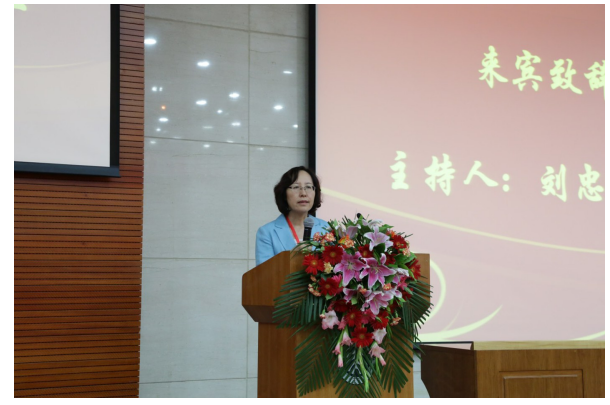

吴海鹰教授致辞

(c) Editorial office of Acta Physico-Chimica Sinica 


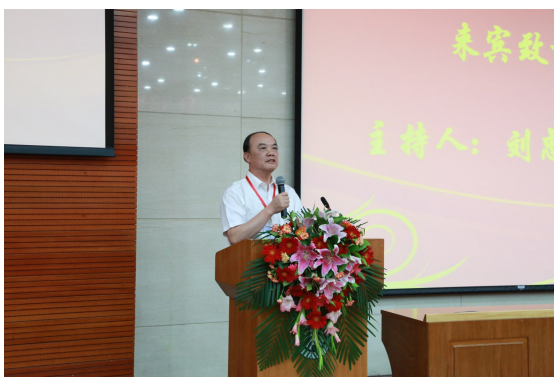

姚建年院士 致辞

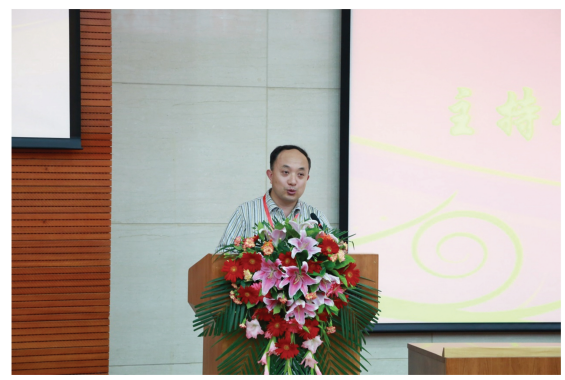

杨俊林研究员 致辞

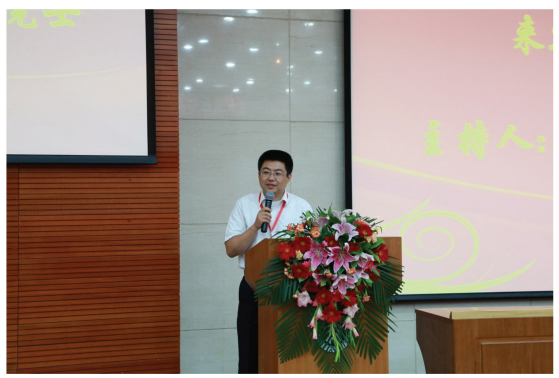

高毅勤教授 致辞

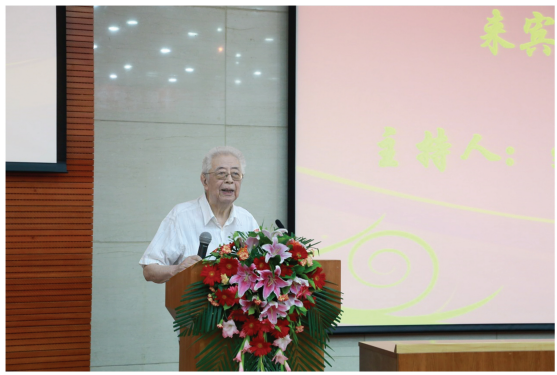

张存浩院士 致辞

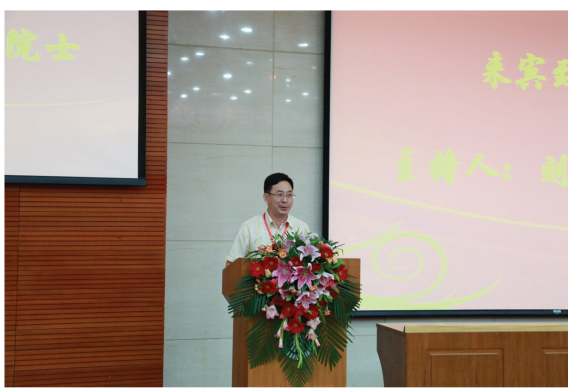

张德清研究员 致辞

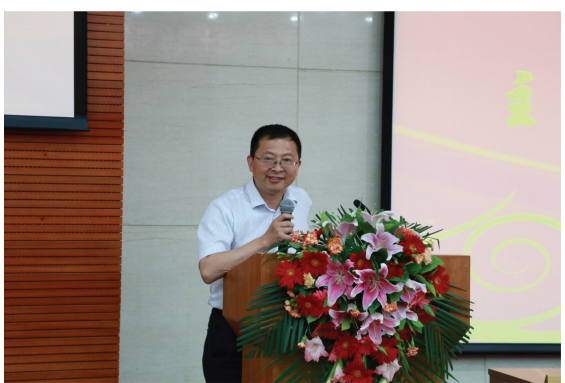

高松院士 致辞

高毅勤院长主持聘任仪式, 聘请学报创刊主编唐有祺院士为名誉主编, 并颁发水晶纪念盘; 聘任刘 忠范院士为新一届主编; 聘请包信和院士、段雪院士、付贤智院士、侯建国院士、黄维院士、Charles M. Lieber 教授、田中群院士、万立骏院士、吴云东院士、谢晓亮教授、杨伟涛教授、姚建年院士和赵新生教授 为学报顾问编委; 聘请韩布兴院士、刘鸣华研究员、申文杰研究员、吴凯教授、杨金龙教授和庄林教授为 副主编以及 49 名来自国内外物理化学领域专家学者组建成的新一届编委。会议向新任的主编、顾问编 委和编委会成员颁发了聘书。

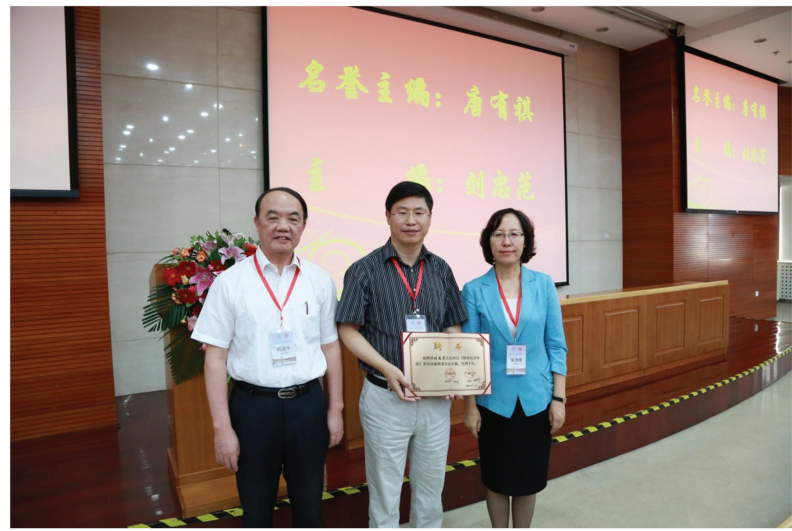

颁发主编证书 
随后, 刘忠范主编代表学报做了“砥砺奋进, 勇创辉煌—《《物理化学学报》三十年之旅” 的报告, 回 顾了学报自创刊以来一步一个脚印、不断成长的历史轨迹, 感谢过去三届编委会成员以及学报全体编 辑人员做出的历史贡献,并对学报的未来发展勾勒了新的蓝图。副主编吴凯教授主持报告会。

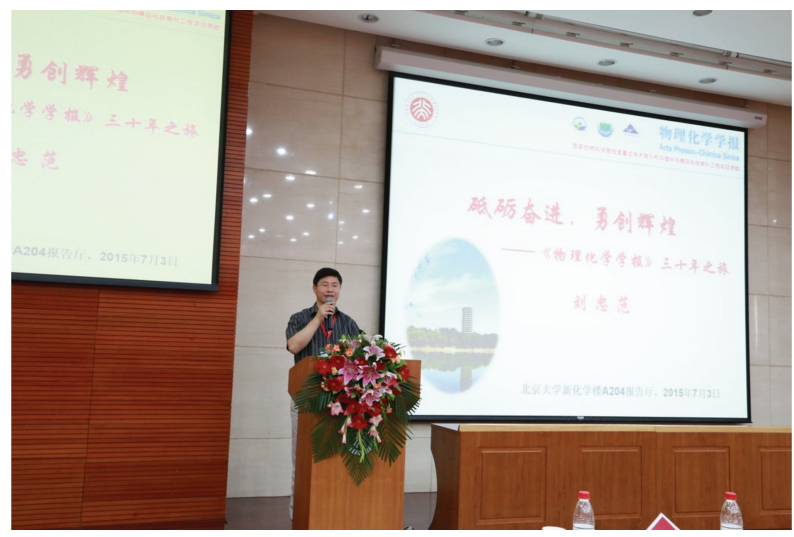

刘忠范主编 报告

7 月 3 日下午 4 点召开了第四届编委会会议。编委会成员听取了编辑部主任欧阳贱华副编审所做 的关于编委会换届的情况说明, 审议并通过了於秀芝副编审所做的新的“《物理化学学报》编委会章 程”, 讨论了 2015-2016年度的编委会工作计划。编委们就学报的办刊特色、办刊理念、办刊目标以及 办刊措施进行了热烈交流讨论, 并提出了一系列建设性意见。

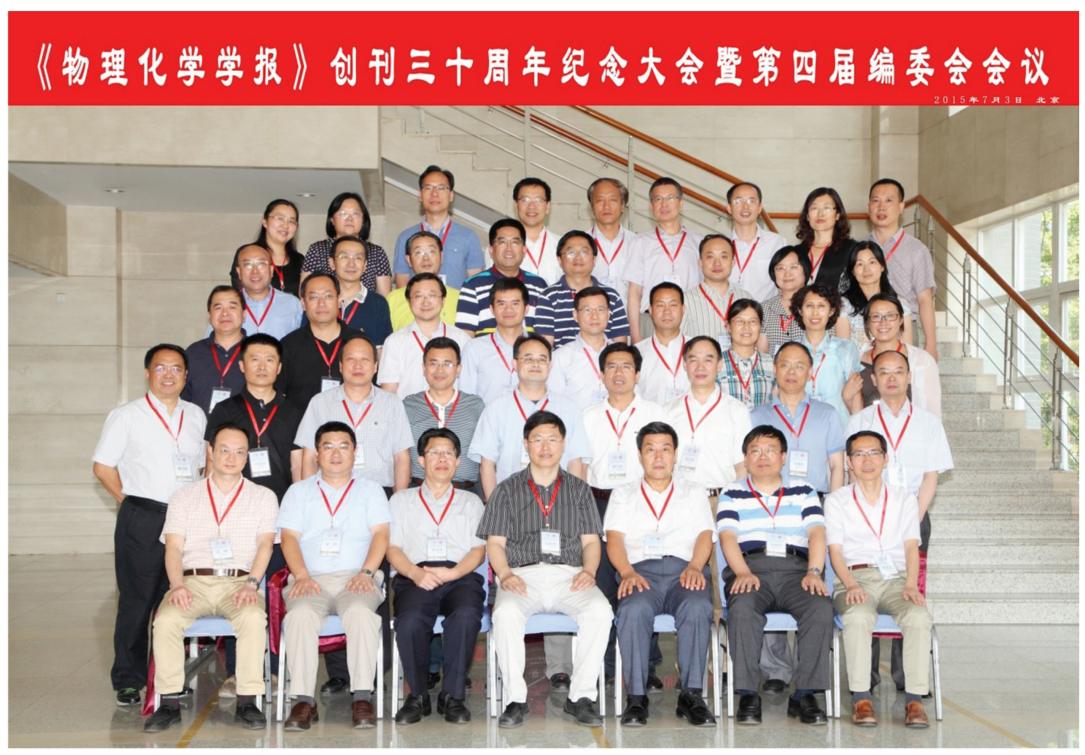

第四届编委会与会代表

7 月 4 日,在化学与分子工程学院 A204报告厅举行了“物理化学前沿学术研讨会”。刘忠范院士、 物理化学研究所所长来鲁华教授、副所长刘海超教授和黄建滨教授主持报告会。会议邀请了新一届编 委会成员, 厦门大学田中群院士、中国科学院化学研究所韩布兴院士、湖南大学谭蔚泓教授、南开大学 陈军教授、中国科学院大连化学物理研究所申文杰研究员、中国科学院武汉物理与数学研究所邓风研 究员、中国科学技术大学杨金龙教授以及北京大学吴凯教授等八位专家分别就物理化学的相关前沿领 域报告了他们的最新研究成果。这些精彩的学术报告引起与会专家学者和化学与分子工程学院师生 们的浓厚兴趣, 并开展了热烈的学术交流与讨论。 
背景介绍

《物理化学学报》是由中国科学技术协会主管、中国化学会和北京大学主办、依托于北京大学化学 与分子工程学院的专业期刊。1983 年, 筹备办刊; 1984 年, 国家科委正式批准; 1984 年成立第一届编委 会, 唐有祺院士担任创刊主编; 1985 年 2 月出版创刊号。学报一经出版即被 CA收录, 并于1997年被美 国 ISI 的 SCI 收录, 是我国最早入选 SCI 的少数中文学术期刊之一。学报至今已被国内外近 10 个数据 库收录。《物理化学学报》是我国物理化学学科十分重要的专业科技期刊之一, 已成为我国物理化学界 广大科技工作者和研究生提高学术水平、交流学术思想、借鉴研究经验和相互学习的重要园地, 是中国 物理化学研究走向世界、世界认识中国物理化学研究的一个重要窗口, 也是有关企业用来指导生产和 科研开发的重要参考。在科协主管的 400 多种科技期刊中，《物理化学学报》因其优异的品质和重要的 学术影响屡获嘉奖。例如, 学报于1992年获“中国科协优秀科技期刊奖”和北京市新闻出版局“全优期 刊”, 连续荣获中国科协期刊优秀学术论文奖, 自 2008 年至今已连续 8 年荣获中国科协精品科技期刊工 程项目资助。《物理化学学报》在新闻出版总署优秀期刊的评选中㭉获国家期刊百种重点期刊奖, 同时 连续两次获国家自然科学基金委期刊专项基金资助。《物理化学学报》已于 2007 年实现所有过刊全文上 网。 